\title{
Beyond Mood and Modality: Epistemic Modality Markers as Hedges in Research Articles. A Cross-Disciplinary Study
}

\author{
Ignacio Vázquez and Diana Giner \\ University of Zaragoza / San Jorge’s University \\ ivazquez@unizar.es / dginer@usj.es
}

\begin{abstract}
In this paper a cross-disciplinary study of the use of epistemic markers as hedging rhetorical strategies in research articles in English is carried out. Based on computer readable data, and combining quantitative and qualitative methods, the article argues that the use of modal expressions can be better explained as reflecting the strategies of hedging used by writers for dealing with the social conditions involved in the event of publishing an article, which is addressed to different discourse communities. Three different disciplines (Marketing, Biology and Mechanical Engineering) belonging to the soft knowledge vs. hard knowledge discipline continuum are investigated here. Our analysis of hedging in these three different disciplines has revealed, not only that there are differences in the occurrence of hedges in the RAs selected, but also that these differences depend on the nature of the data used for the research in each discipline. Each discipline tries to fulfil social needs in different areas. The sociological features of each discipline may be shaping the discourse in their RAs differently. This is reflected in the varied presence of hedging devices in Marketing, Biology and Mechanical Engineering research articles.
\end{abstract}

\section{Introduction}

This article explores the role of epistemic modality markers in research articles taken from three different disciplines: Marketing, Biology and Mechanical Engineering. 
These can be studied as the most common realizations of two rhetorical strategies, whose dominant function is the qualification of the writer's commitment (boosters) or lack of commitment to the truth of a proposition (hedges). Here the expression of hedging through epistemic modality markers will be examined.

Based on computer readable data, and combining quantitative and qualitative methods, the article argues that the use of modal expressions can be better explained as reflecting the strategies of hedging used by writers for dealing with the social conditions involved in the event of publishing an article, which is addressed to different discourse communities. Three different disciplines belonging to the soft knowledge vs. hard knowledge disciplines continuum will be investigated here.

Hedging is a common feature of scientific communication. "Academic discourse is a world of uncertainties, indirectness, and non-finality - in brief, a world where it is natural to cultivate hedges" (Mauranen 1997: 115).

Although hedges are still very problematic to define precisely, the status of hedging is well documented in academic genres (Hyland 1998), and this is especially visible in research articles.

Here we adhere to Hyland's taxonomy of metadiscourse (Hyland 2005a), in which hedges are considered as a separate category from that of boosters. The high occurrence of hedges in research articles is justified by the assumption that they can fulfil a number of functions, such as projecting an image of honesty and humility (Swales 1990:433), conveying vagueness and tentativeness to make propositions more acceptable to readers (Salager-Meyer 1994:150), expressing positive and negative politeness (Myers 1989, Varttala 1999) or negotiating the right representation of the state of knowledge discussed (Banks 1994).

The use of hedging techniques in research articles has normally been investigated by looking at grammatical and lexical units, such as modal auxiliaries, epistemic verbs and adjectives, epistemic nouns or adverbial expressions of probability, possibility and necessity, which together are often referred to as modal meanings, or more simply, modality.

\section{Modality and Hedging}

The concepts of modality and hedge thus overlap to a lesser or greater extent depending on their respective definitions. This connection is very clear in the case of modal verbs with epistemic meanings. When hedges are taken to be modifications of the commitment to the truth-value of propositions, for example, the English modal auxiliary may is always listed as a typical example. Thus, in It may be true it is a hedge but also an expression of epistemic modality. Sometimes also the deontic meanings of modals allow interpretation as hedges. For example, in English the hypothetical would could be seen as a hedge because it makes an utterance non-categorical. Preisler $(1986,92)$ actually points out that "even when modal forms convey speaker-external meanings, these are often given interpersonal significance by the particular context in which they appear, usually as part of a tentativeness strategy". It seems possible to see the 
relationship between modality - mostly of the epistemic type- and hedges in two ways: either modality is the wider concept and includes hedges or the other way round, hedging is the umbrella term and epistemic modality a part of it.

Traditional characterizations of modality construe these values in overtly individualistic terms and are too narrowly concerned with issues of truth-value and epistemic reliability. Those characterizations are obviously useful in that they help us understand certain interpersonal aspects of discourse.

Much of the literature on modality (Coates 1983, Perkins 1983, Lyons 1977, Palmer 1986, Chafe and Nichols 1986) often assumes that the sole function of modals is to reveal the speaker/writer's state of mind or knowledge, to indicate that the speaker/writer is uncertain or tentative and is not committed to the truth value of the proposition.

Jennifer Coates (1983) makes a distinction between epistemic and root modality. Even though she acknowledges the further division of root into dynamic and deontic modalities, she focuses on epistemic and deontic for the purpose at hand. Both can be placed on "gradable scales", one depicting varying degrees of "impossible-possible necessary/certain", the other "forbidden-permitted-obligatory". The distinction between epistemic and deontic modality is often treated as the most salient, and here we will concentrate on epistemic modality and its markers. Markers of epistemic modality are generally more common in academic writing than in conversation (see Biber et al. 1999, 48 3ff.).

The term "epistemic modality marker" refers to linguistic elements, whose main function is the qualification of the writer's commitment (boosters) or lack of commitment (hedges) to the truth of the proposition. In this article we explore the use of epistemic modality markers as an expression of hedges in research articles written in English and belonging to three different disciplines (Marketing, Biology and Mechanical Engineering).

Drawing on the concept of "metadiscourse" (Crismore 1989, Hyland 2005), we concentrate on the interdisciplinary analysis of epistemic modality markers, which contribute to the expression of writer's stance in academic writing, with a special reference to the category of hedges.

\section{Hyland's Metadiscourse Model}

In this paper we have adopted Hyland's view of metadiscourse, as “the cover term for the self-reflective expressions used to negotiate interactional meanings in a text, assisting the writer (or speaker) to express a viewpoint and engage with readers as members of a particular community" (Hyland, 2005: 37). Since the purpose of this paper is mainly to analyse the ways in which some communicative acts are carried out in RAs (research articles) belonging to different disciplines, Hyland's definition results particularly interesting for emphasizing the interpersonal function of language. In accordance, Hyland's classification of metadiscourse deals with the ways in which writers create different functions in their discourse. His model takes into consideration 
two dimensions of interaction: the interactive dimension and the interactional dimension. The first one is related to the way the writer or the speaker organises the information presented according to the audience. That is, the way the information is disposed will depend on the knowledge of the reader, the genre, etc. The function of metadiscourse elements here is to shape the information in order to meet the expected needs of the audience. The interactional dimension is more related to the actual communicative functions that the author wishes to transmit the audience. In this dimension, the function of metadiscourse elements will generally consist in modulating certain statements and enhance others with the main purpose of defending the author's conclusions and convincing the audience of their truth.

Among the interactional elements of metadiscourse we can find a sub-classification according to their specific function: hedges, boosters, attitude markers, self-mentions and engagement markers. Since this work is focusing on the presence hedges, we will only dedicate some space in the next chapter to their definition and functions.

\subsection{Interactional elements in RAs}

A major characteristic of academic discourse is the presence of elements whose purpose is to modulate assertions or to emphasise statements. This epistemic dimension of interactional elements allows researchers to, somehow, lead the readership to interpret the statements present in a Research Article (RA) in the way the author desires. The immediate consequence and purpose of this is to reach the final communicative purpose of text: to convince the readership of the consequences or findings resulting from the data analysed by the author. The information given has been exposed taking into account two important aspects for the right guidance of the audience. On the one hand, the author will have put stress on the factors that influence the final conclusions. On the other hand, risky assertions will have been modulated appropriately.

\subsubsection{Hedges: definition and functions}

These linguistic elements have the purpose of offering room for negotiation. They open the door to alternative views for the statements presented. They permit that a proposition is rather recognised as an opinion instead of a clear affirmation. Writers will highly consider the amount of certainty they should put in a particular statement according to the amount of reliable data backing this statement.

The use of hedge as a linguistic term goes back at least to the early 1970s, when G. Lakoff (1972: 270) published his article Hedges: A Study in Meaning Criteria and the Logic of Fuzzy Concepts. Since the early 1970s the concept of hedge has moved far from its origins, particularly since it has been adopted by pragmaticists and discourse analysts, who have taken hedges to be modifiers of the speaker's commitment to the truth-value of a whole proposition. Vande Kopple (1985) categorised hedges as the elements providing "lack of full commitment to the propositional content of an utterance. In other words, hedges (e.g. perhaps, seem, might, to a certain extent) are by him seen as modifying the truth-value of the whole proposition, not as making 
individual elements inside it more imprecise” (Markkannen et al., 1997: 4-5). In other approaches the original hedges are treated as realisations of an interactional/communicative strategy called hedging. Thus, Markkanen/Schröder (1989; 1992), who discuss the role of hedges in scientific texts, see them as modifiers of the writer's responsibility for the truth value of the propositions expressed or as modifiers of the weightiness of the information given, or the attitude of the writer to the information. According to them, hedges can even be used to hide the writer's real attitude. Markkanen/Schröder also suggest that hedges offer a possibility for textual manipulation in the sense that the reader is left in the dark as to who is responsible for the truth value of what is being expressed (Markkannen et al., 1997: 5).

One major characteristic that hedging provides is modality. Modality is very much epistemologically related since it deals with the relativity of a particular truth or knowledge. Academic research has contributed to the definition of hedging in relation to modality. For example, Lyons (1977: 797) describes it as "any utterance in which the speaker explicitly qualifies his commitment to the truth of the proposition expressed by the sentence he utters (...) is an epistemically modal or modalised utterance”. Thus, modality is a concept that may be directly reflected with the presence of hedging in a discourse. As well as modality, there are other epistemological concepts related to hedging. These are evidentiality and vagueness. According to Markkannen (1997: 7), a statement is considered evidential depending on how broadly the hedging is understood by the reader. That is, the reliability of a proposition or the amount of truth it possesses is subject to the interpretation of the audience that receives it.

\section{Hedging in Academic Writing}

There has also been a growing interest lately in hedging and the motivation for its use in academic/scientific writing. The interest is focused on that hedges are actually used in scientific discourse, which is supposed to be above all rational and neutral. This is connected with the fact that scientific discourse obeys the same mechanisms as ordinary everyday communication does, although it tries to hide this, more or less successfully, by using a code of its own. We assume here that science is not only content; that is, scientific texts are not only content-oriented and informative but also aim at convincing and influencing their audience. According to classical rhetoric, formulation of a scientific text is not merely built on docere (instructing, informing) but also on delectare (entertaining) and movere (moving, enchanting). Thus, in addition to 'going into the subject matter' (pragma), a text should also emphasize the reliability of the author (ethos) and also move the reader emotionally (pathos). The last two, ethos and pathos, are closely connected with the expressions used in the text, including hedging. The rhetorical style of a scientific text is not merely a decorative addition to an otherwise informative text; rather form and content are inseparable.

Varttala states in his work (2001: 67) that the reasons for the use of hedges in academic writing lie in the fact that this type of writing must be prepared to confront a rather not sympathetic response of the audience. Academic writing should be able to 
enhance the author's credibility constructing a reliable description of the researcher's analysis. In this manner, persuasion becomes a rather fundamental ingredient for the consecution of this purpose. As Varttala says, "this need apparently rises from the requirements imposed upon the RA author by the assumed degree of the audience's background knowledge and the possibility of opposing views on the part of the readership, it being clear that alongside the theories and methods preferred and conclusions drawn by one scientist or group of scientists, there may exist other approaches to the phenomenon under scrutiny” (2001: 67). From a similar perspective, Maher (1992) offers valuable advice in relation to hedging for the creation of conclusions in medical academic writing. He states that a conclusion "may be hedged in which the author carefully avoids giving a direct and strong commitment to a position or point of view but without seeming too vague. [...] An author may not want to state something too definitely or concretely. The writer might simply wish to suggest an interpretation or point as likelihood. This is a strategy for writing about data which not only allow for the possibility of alternative interpretations, but also partly shelters the author from strong criticism” (Varttala, 2001: 69).

Various works addressed for academic writers and students focus on the idea that this type of discourse should be kept as neutral as possible and even enhance the presence of more impersonal statements. Moreover, the use of vagueness is recommended to be avoided. Varttala illustrates this trend in his work quoting several authors who support this theory (2001: 54). “Alley (1987: 28) is of the opinion that precision is the most important goal in scientific language and that vagueness should be avoided, and Hedge (1994: 92) states that directness, precision and objectivity are among the central guidelines for scientific writing”. According to this course of action, the use of hedges seems to be an undesirable feature in the construction of academic writing. In fact, some scholars have stated a more straightforward approach regarding these epistemic elements. If we take for instance the work of Bolsky (1988: 61-62), he advises the authors of scientific texts to avoid the use of "hedge words" (e.g. may, perhaps, seem) and encourages writers to use "direct words" to explicitly indicate if they are not certain about the accuracy of what is said (e.g. I believe ... but can't be sure). Booth (1985: 11) is also in favour of the avoidance of hedging in scientific discourse. He [...] "too, warns those engaged in scientific discourse about the dangers of overflowing hedging, implying that if a person writing for publication has to hedge, it is questionable whether he or she is truly ready to publish (Varttala, 2001:54).

Bazerman (1984: 163-164) also makes his contribution to the construal of guidelines for academic writing from the perspective of a neutral speech. More specifically, he sets out a series of directions for "ideal" scientific writing according to how language has been used traditionally for this purpose:

1. the scientist must remove himself from reports of his own work and thus avoid all use of the first person;

2. scientific writing should be objective and precise, with mathematics as its model; 
3. scientific writing should shun metaphor and other flights of rhetorical fancy to seek a univocal relationship between word and object; and

4. the scientific article should report its claims with empirical evidence from nature, preferably experimental [...]

Alternatively, some other scholars have appreciated much more the use of hedging in academic writing. The connotations of vagueness and imprecision it conveys to the discourse are considered useful by them when it comes to report scientific research appropriately.

On the whole, hedges can provide academic writers with a variety of resources for the building of their discourse in a text. Writers may find these concepts valuable for their discourse. However, regarding socio-linguistic conventions, the presence of politeness results particularly important in texts addressed to academic communities. This concept has particularly been appreciated by Myers (1989), who was among the first to observe its use in scientific discourse. He paid particular attention to the use of politeness markers, including hedges and their functions in this type of discourse. As Varttala states (2001: 69), Myers considers the idea that hedges "may be employed to protect negative face [...] founded on the rationale that, [...] the authors of such texts may feel a need to assure the readers that the ideas put forth are not intended to exclude alternative views. By hedging information pertaining to those aspects of RAs that might give rise to objections, authors can mark a claim, or any other statement, as being provisional, pending acceptance in the literature, acceptance by the community- in other words, acceptance by the readers” (Myers 1989: 12). In this sense, hedging plays a fundamental role for its ability to keep the distance between what is being said and the actual writer's opinion, therefore, avoiding any possible conflicts that could be originated from the statement of an explicit, absolute truth. Thanks to the construction of a text where different perspectives may be accepted, the statements contained in that particular discourse may be more likely to be considered true. As Hübler (1983) affirms, "The function of hedges is to reduce the risk of negation. Thus, it can be claimed that, in all communication, while showing deference to the addressee, the speaker or writer also tries to protect him/herself from potential anger, contempt or other humiliation on the part of the addressee” (Markkannen et al., 1997: 8). For this reason, hedging is also considered a useful tool for the creation of social distance in matters of power relations in certain disciplines.

\section{Cross-disciplinary Analysis of Hedges: a corpus-based study of RAs in Marketing, Mechanical Engineering and Biology.}

\subsection{Corpus Analysis}

In order to carry out the analysis we selected 12 research articles of different disciplines. The first discipline we selected belongs to the soft sciences (Marketing), the second one comes from the area of hard sciences area (Mechanical Engineering) and, 
finally, the third discipline (Biology) could be located in a middle point within the continuum. That amounts to 23,724 words; range in the Marketing articles, to 39,537 in Biology and to 12,657 words in Mechanical Engineering. The aim of our analysis is to find out whether current authors of RAs in these disciplines actually make use of these words charged with modal value.

\section{2. A cross-disciplinary perspective}

Academic writing is created by paying special attention to the specific constraints or conventions of different disciplines. These constraints condition the actual resources used by academic writers in their different disciplines. Scholars' work is reflected in academic discourse through a selection of linguistic elements; and this selection is made respecting the conventions or rules existing within that particular discourse community. These conventions might ensure academic writers that their work is actually recognised by readers and accepted by their colleagues in that discourse community. As Varttala states (2001: 248) "different disciplines may not be altogether uniform when it comes to frequency, forms, and variety of hedges”. In this way, hedging in Medicine may not possess the same occurrence as in Linguistics or Biology. Some scholars think differently; for instance, McCloskey (1994: 120) suggests that the difference of hedging occurrence in various disciplines is not so significant. However, other scholars have postulated that the use of hedging varies in accordance to the discipline where the academic writing is settled. Among these researchers we can find Bloor and Bloor (1993) or Backhouse (1993). These researchers have carried out specific studies revealing that the differences are remarkable. For example, Bloor and Bloor find little hedging in the academic discourse of economics where it would have been employed in other disciplines. In the same way, Backhouse (1993: 15) affirms that authors within the subject area of Biology appear to have the need of a more frequent use of hedging elements in their discourse. In Varttala's work itself (2001: 249) he states that "the overall incidence of hedges was highest in the field of economics, whereas the relative overall number of hedges in medicine and technology was about one third lower". In general terms, the results of his studies reveal that academic writing in "soft sciences" maintain a higher rate of hedging than those known as "hard sciences". He affirms that the underlying reason for this difference is mainly the varied nature of sciences. On the one hand, hard sciences demonstrate their results with more exact research methods such as measurements or calculations of numerical data. This leads to more certain or "safer" statements, in the main part, lacking imprecision. According to Varttala, technology seems to be the most numerical science and, consequently, this is reflected in the little frequency of hedging in its discourse. On the other hand, the nature of the research material in soft sciences, generally speaking, cannot be mathematically verified. Thus, the outcoming results or conclusions are more likely to find contradictory opinions from other research fellows or academics in the field. Following this, authors of soft sciences might find it more daring to make too declarative statements. These data tend to be more subject to the author's and audience's interpretation. For this reason, the results sections of these RAs are more likely to 
include more hedging elements than the rest. Researchers in soft sciences may not be able to show the same confidence as researchers of hard sciences. Hedging elements, therefore, seem to be more in need when constructing new knowledge due to the uncertain ground of the subject areas.

\subsection{Analysis}

Taking into account the present ambiguity on whether it is advisable or not to use hedges in academic writing, we have selected research articles of different disciplines as analysis material. The first discipline we have selected could perfectly belong to the soft sciences (Marketing), the second one should be placed in the hard sciences area (Mechanical Engineering) and, finally, the third discipline (Biology) could be located in a middle point within the continuum. The aim of our analysis is to find out whether currently authors of RAs in these disciplines actually make use of these words charged with modal value.

For the analysis, we have chosen Hyland's taxonomy of hedges which he used himself in his research (2005: 218). This taxonomy does not make any distinction in relation to lexico-grammatical categories, which makes it more suitable for our analysis, merely centred on the calculation of the presence of these elements regardless of their category. The list he has composed for hedges is the following:

\section{Hyland's hedging items.}

About, almost, apparent, apparently, appear, appeared, appears, approximately, argue, argued, argues, around, assume, assumed, broadly, certain amount, certain extent, certain level, claim, claimed, claims, could, couldn't, doubt, doubtful, essentially, estimate, estimated, fairly, feels, felt, frequently, from my perspective, from our perspective, from this perspective, generally, guess, indicate, indicated, indicates, in general, in most cases, in most instances, in my opinion, in my view in this view, in our view, largely, likely, mainly, may, maybe, might, mostly, often, on the whole, ought, perhaps, plausibly, possible, possibly, postulate, postulated, postulates, presumably, probable, probably, quite, rather $\mathrm{x}$, relatively, roughly, seems, should, sometimes, somewhat, suggest, suggested, suggests, suppose, supposed, supposes, suspect, suspects, tend to, tended to, tends to, to my knowledge, typical, typically, uncertain, uncertainly, unclear, unclearly, unlikely, usually, would, wouldn't.

Figure 1 


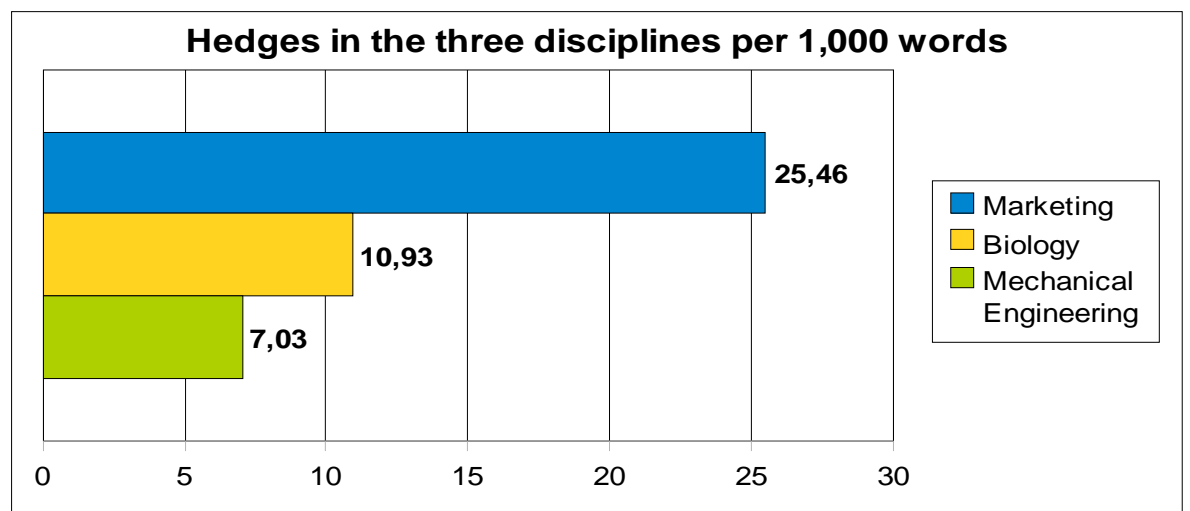

Figure 2

As figure 2 shows, the amount of hedging elements in Marketing (25.46) more than doubles the quantity found in the discipline of Biology (10.93) and more than triples the results in Mechanical Engineering (7.03). These findings match our initial expectations. Marketing is a fairly socially driven subject area that focuses on the habits and conventions of certain communities. One of the main targets of this discipline is to obtain patterns of behaviour in society. This aspect results particularly important for our analysis since it implies that the data contained in the RAs of this discipline will surely not be very numerical or mathematically verifiable, but rather based on opinions. Furthermore, this discipline is nurtured by other social sciences such as Psychology, Sociology or Anthropology. Consequently, and as it had been concluded before by other scholars, the nature of this science seems to strongly influence the use of interactional elements like hedges, in this particular case.

Thus, Marketing researchers may make a wider use of hedging elements to handle results that are very much subject to interpretation and strongly influenced by contextual factors. On the other hand, Mechanical Engineering, as a hard science, should not include a great amount of hedging elements due to the precise nature of the data this discipline is nurtured with. Never the less, the amount of hedges found in Mechanical Engineering is not insignificant and will surely be supported by strong reasons. (We will analyse these reasons later in this paper through a context analysis). The moderate findings of hedging elements in Biology may be explained again by the diverse nature of its research data. Whereas we could perfectly classify Marketing as a soft science and Mechanical Engineering as a hard science, Biology does not clearly stand on any of these two categories. Looking into the nature of the data used for analyses within this science, one soon realises there are varied disciplines involved. Such are the examples of Biochemistry, Psychiatry, Zoology, Sociobiology or Mathematics; areas that might be involved in many biological animal studies, for example. These disciplines belong to either soft or hard sciences. As a consequence, the data obtained from researches taking place in Biology will result of mixed nature.

The figure of the percentages of hedging elements found in the three disciplines (Figure 3) visually reveals the great disparity in their use. We can observe that the amount of hedges in Marketing is more than double the quantity found in Biology. 


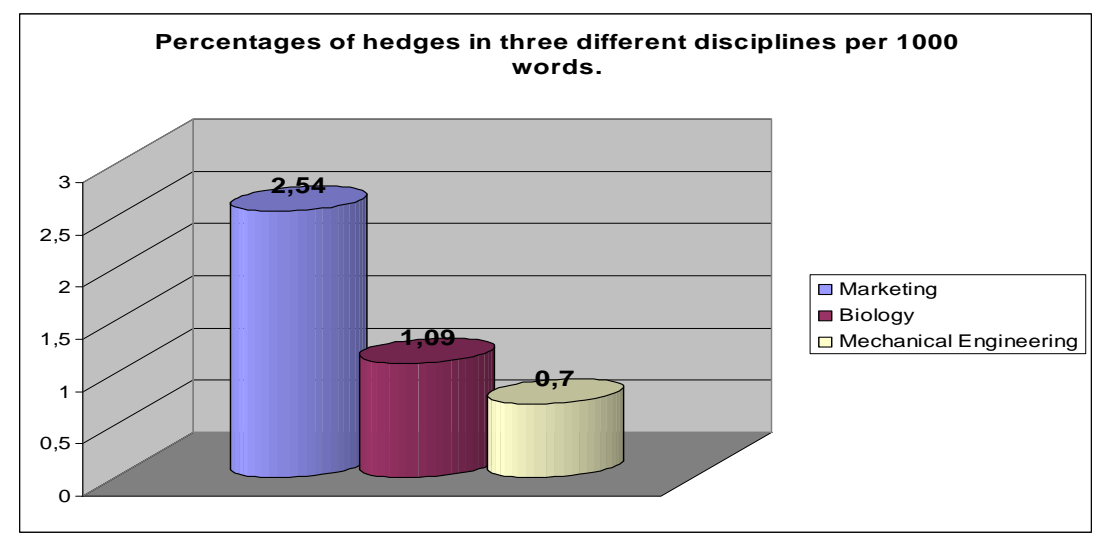

Figure 3 Percentage of Hedges in Marketing, Biology and Mechanical Engineering.

\subsubsection{Hedges in Marketing}

In this first paragraph [1] we find three tokens of hedging elements. In the first one we observe that the author seems to be trying to modulate his statement. The result is that the audience will not interpret his proposition as being categorical. It also shows the author is aware of the possible alternative ways to interpret his results. In addition, the author is perhaps trying to be modest when describing his achievements. The second token "appears" modulates the proposition with the noticeable intention of not wishing to sound too sharp. The main reason behind his intention might be focused on the presence of diverse research outcomes. In the third example the author is showing lack of accuracy when affirming that Gale was the first to reach such results. The author is probably sure of this fact, yet he prefers to leave it subject to the audience's interpretation since there is not absolute evidence that such a statement is completely true. All these propositions appear modulated mainly due to the abstract nature of the data involved in the analysis of the article. On the other hand, particularly in the first token, the author is also conveying a sense of politeness necessary, especially, to fulfil the conventional needs of this genre.

[1] We are perhaps some way to achieving a similar framework regarding satisfaction (see Oliver, 1997; and Giese and Cote, 2000) but consensus regarding the nature of VC still appears distant. Witness, for instance, the current lack of unanimity concerning measurement. Gale (1994), perhaps the first to attempt quantification of value in a marketing context, uses a mapping process that enables a supplier to benchmark the 'value' of its market offering with that of its competitors through a comparative review of customer's perceptions regarding both product price and quality. (Woodhall, 2003: 3)

In the second example [2] the author is again trying to modulate his statement where the results of his analysis are involved. By not affirming that his research does actually 
raise key issues, he is conveying politeness by adopting a not authoritarian posture and willing to accept other points of view. This variety of perspectives is particularly possible because of the abstract data involved in this discipline.

[2] In order to clarify the implications for researchers in adopting the approach we have outlined, we will next summarise the key issues our suggested research topics raise. (Peters, 2004: 18)

The rather unreliable nature of the data of this discipline is again exposed in example [3]. The four tokens express the ambiguity related to the abstract data used in the analysis. Conversely, a sense of politeness is also brought to the discourse thanks to these interactional elements.

[3] That is, the buyer might choose a popular option on sale instead of trying to understand the attributes in the category and predict the goals of the person receiving the gift. Then the attribution style assumed for self-blame is perhaps quite likely. (Desmeules, 2002: 14)

Hedges are used to convey vagueness and politeness in order to avoid confrontation between author and audience in example [4]. In this manner, there is still room for negotiation.

[4] [...] in the future, this framework may well be altered through the addition of rich and revealing depth interviews. Such interviews may add data for the assessment of the logical linkages between text derived coded constructs. (Latour, 2003: 9)

In example [5], we can see another case of ambiguity conveyed thanks to the hedge “could”, which allows a more dialogic interpretation between writer and readership.

[5] The "point of satisfaction" could be attained with one option alone, providing it fulfills the needs of the consumer. As satisfaction is reached, we enter a plateau section where options can be considered (or ignored) without much affecting the positiveness of the experience. (Desmeules, 2002: 1-2)

\subsubsection{Hedges in Mechanical Engineering}

Hedging has come to be seen as a key characteristic of academic discourse, no matter whether we refer to such hard sciences as Mechanical Engineering. Although less frequently used than in other disciplines, we have found a series of tokens within this discipline. It appears that authors feel the need to introduce these elements in their discourse for one reason or another. We will proceed to analyse a sample of them to try and identify the intentions of the authors. 
In example [6] we can recognize the use of hedging with the apparent author's intention of showing uncertainty in the view of alternative perspectives regarding the interpretation of the analysis. The author is making a recommendation to the readership; he is being careful of not conveying a rigid description. This brings politeness to the discourse.

[6] The strain gauge element length, i.e. its finite dimensions, can also significantly influence the evaluated calibration coefficients in terms of non-linear displacement spatial dependence. This fact should not be omitted and the real strain gauge element length of a rosette used by measurement should be considered. (Svantner, $2003: 14)$

In the following examples [7] and [8] we can identify a similar function in the authors' use of hedging. In these cases, the authors are also trying to transmit an implicit recognition of alternative voices in their method of procedure. Politeness is, of course, also implied in this action.

[7] The lenses of the camera cause distortion. With better quality lenses the distortion could be decreased. (Hegyi, 2005: 3)

[8] The contact may destroy some symmetry properties of the solutions. (Gaspar, 2005: 1-2)

In example [9], the author is showing a dialogic interpretation in the analysis. Even though the data seem to be numerical and precise, the author still prefers to leave room for negotiation. At the same time, he is also conveying politeness.

[9] We consider a plate $(5 \mathrm{~cm})$ for which the thermal conductivity is assumed to be a linear function: , $=a T+b$, where $a={ }_{i} 0: 04023 ; b=60: 916$ [...] (Mochnacki, 2005: 5)

In the following example [10] the author is again trying to avoid rigid propositions where only his perspective is possible. By introducing "would" in his sentences, the meaning of the propositions appears modulated and open to alternative interpretations. Thus, a sense of politeness is as well present in the discourse.

[10] [...] because on the top of the loop the rod would have too high a curvature. This would lead to an overlap at the top of the loop, as can be seen in Figure 3. (Gaspar, 2005: 7)

On the whole, we can talk about politeness conveyed through ambiguous propositions that are open to negotiation. The authors may be certain in their assumptions and findings and their data are rather easy to be verified (in contrast to softer sciences). Yet, 
they still prefer to leave some room for alternative interpretations. In this way, a possible confrontation between the writer and the readership is avoided. By allowing the possibility of alternative viewpoints, the author's propositions will not be immediately negated whereas new pieces of knowledge might be built upon these modulated statements, allowing a more assured flow of information. Since propositions concerning new knowledge might not be considered absolute truths, they will probably at least make a contribution for the knowledge construction within the discipline.

\subsubsection{Hedges in Biology}

The results from his analysis do not appear to be completely accurate and reliable. In this discipline, as it could happen in other "mixed disciplines" such as Medicine, for example, mathematical rules do not always result effective for a successful resolution. There are other factors that need to be considered when taking into account a biological study. These are related to other softer sciences like the case of social or psychological causes, environmental conditions, or even unpredictable biological factors. In consequence, biological data are not entirely controllable and calculable.

In example [11] we can find two tokens of hedges by which the author conveys ambiguity to the statements. He seems to be aware of the existence of other possible interpretations on the topic. Even though the data appear to be easily calculated, there are external factors influencing the results that may not be so easily predicted. Thus, there is a preference to use a less involved attitude towards the propositions presented.

[11] In a murine model of asthma, examination of CD28-deficient mice or treatment of wild-type animals with a soluble reagent, CTLA4Ig, that prevents B7 from binding either CD28 or CTLA4 abrogated both airway inflammation and hyperresponsiveness, suggesting a critical role for this pathway in the pathogenesis of the disease. Thus, the manipulation of T-cell co-stimulation may be an effective strategy in the treatment of airway inflammation. (Huey et al., 2007: 1)

Example [12] shows the author's uncertainty about what is being stated. Let us notice that, however, the proposition is related to the author's previous own findings. Consequently, the reasons behind his decision to use hedges in these propositions may be due to two main reasons. On the one hand, he is aware of the alternative perspectives that may be regarding the topic. On the other hand, the author also wishes to convey a level of politeness as the conventions for RA writing demand.

[12] However, the degree of coupling is unclear. Austin et al. (1992) showed that a doubling of $\mathrm{CO} 2$ concentrations, expected towards the end of the 21st century, could lead to severe Arctic ozone loss if large halogen abundances persisted until that time. (Austin et al., 2003: 2)

Examples [13] and [14] in our analysis are similar to example [12]. The data involved in the author's conclusions are of mixed nature. There are variables that cannot be 
completely controlled and calculated. There is a margin of error that influences the language used in the academic writing of this discipline. In consequence, these authors are more likely to use hedges that make their statements less categorical or declarative.

[13] The results are also compared to determine the possible future behaviour of ozone, with an emphasis on the polar regions and mid-latitudes. (Austin et al., 2003: 2)

[14] The identification of a single process which might be responsible for the observed fluctuations in atmospheric CO2 and _13C cannot be based on a Keeling plot analysis. Most processes acted simultaneously on the global carbon cycle during the transition and the uncertainties in data retrieval, y-axis25 intercept, and _13C are too large to come to a sound and unequivocal process identification. (Köhler, 2006: 35)

In example [15] we can observe that the author's findings are related to the discipline of Chemistry. In consequence, the data should be rather accurate and reliable. The results are not as subject to be influenced by external factors as in other examples above within this discipline. In this manner, the function of hedging in this particular example may not be so much that of conveying vagueness due to the possible alternative voices. The author's main intention in this example may be to bring a certain degree of politeness to the discourse. The author may be again sure about his findings; however, he still considers the modulation of his propositions suitable.

[15] Recent work indicates that CTLA4 may directly influence both Th1 and Th2 cell development (25). CTLA4 ligation inhibits IL-2 and IFN-g secretion in the absence of CD28, but when CD28 is present it may be dominant over CTLA4 (21). (Burr et al., 2001: 5)

\section{Final Considerations}

The process of academic writing is a process of creating new knowledge in order to fulfil the research demands of our society. These demands are diverse and are reflected in the great variety of disciplines existing within the genre of Research Articles. Our results show that the different RAs follow specific patterns. This not only facilitates the process of writing, but it also allows these RAs to be recognised within their particular discourse community. Therefore, conventions concerning the writing process should always be respected. Rhetoric plays a key role in the construction of knowledge within this genre. It helps the unfolding of the text and it becomes essential in order to persuade the audience and obtain a dialogic negotiation of the information conveyed. Interactional elements such as hedges strongly contribute to the consecution of these purposes. Hedges help highlight the subjectivity of a proposition (the fact that a proposition may generally be always subject to interpretation), reducing the author's 
commitment, while adding a certain sense of politeness to the discourse. This contributes to reducing confrontation in the dialogue between the author and other research fellows or academics. At the same time, it also helps the flow of new information. Without the presence of hedges, the text writer would be unable to formulate statements describing new information or creating different viewpoints through persuasion and negotiation of information with the audience. In consequence, the primary communicative purposes of RAs would not be achieved if the absence of hedges were an obstacle to the information flow.

Our analysis of hedging in different disciplines has revealed that not only are there differences in the occurrence of hedges in the RAs selected. We also believe that these differences depend on the nature of the data used for the research in each discipline. Each discipline tries to fulfil different social purposes in different areas. The sociological features of each discipline may be shaping the discourse in their RAs differently. This appears reflected in the varied presence of these interactional elements in Marketing, Biology and Mechanical Engineering.

Marketing is a discipline that bases its statements on data that result particularly abstract. They are mainly originated from observing patterns of human behaviour. The data can be considered, therefore, rather imprecise and sometimes may be interpreted even as unreliable. The function of hedges is mainly to offer room for the negotiation of the information conveyed in the discourse. In this manner, the author admits the diversity of research outcomes allowing that their statements are not immediately negated. The absence of unequivocal statements develops into a situation where immediate confrontations are not so likely to happen. In addition, hedges also express humility and cautiousness bringing politeness to the discourse.

The result of hedges in Mechanical Engineering is very low. Mechanical Engineering belongs to the category of hard sciences. The data handled within this discipline is closely related to subject areas such as Mathematics or Physics. In consequence, the data involved in the analysis and research of Mechanical Engineering is more likely to be precise and accurate than in the case of Marketing or other soft sciences. Some scholars, like Booth (1985), Bazerman (1984) or Bolsky (1988), claim that academic writing should stay aseptic and as objective as possible avoiding all sorts of ambiguous propositions. After all, the readership turns to this source of information to obtain accurate knowledge on the subject area in question. On this basis, we should not expect the presence of hedges. However, we must also consider that there does not seem to be absolute truths. Everything is deemed to be interpreted from different perspectives. In fact, hard sciences construct new knowledge parting from the negation of statements derived from accurate data. In consequence, we should expect the presence of hedges in Mechanical Engineering RAs. Through their use, new information can be constructed.

In contrast to Marketing, the data handled in Mechanical Engineering are regarded as more precise. The authors of the RAs themselves are probably more certain about the truth of their affirmations because of the more reliable nature of their data. Yet, there is 
still an undeniable use of these elements in their discourse. However, we must not forget hedges as messengers of politeness in academic writing.

After the analysis of hedging elements in Biology, our first observations are focused on the data revealing a moderate presence of these elements. Hedges do not appear as frequently as in Marketing; yet, not as rarely as in Mechanical Engineering either. In order to reach conclusions about both the high and low frequency of these interactional elements in those disciplines, we have found extremely useful to pay a special attention to the nature of the data used for each discipline. Biology comprises different subject areas such as Psychiatry, Mathematics, Biochemistry or Sociobiology. In consequence, the data resulting from biological research will be a combination of both accurate and abstract data. Regarding subject areas where the data result more numerical and, therefore, more accurate and precise, hedges have a stronger function to convey politeness to the discourse. Even if the author is certain about the truth of his or her statements, it is highly recommendable for academic writing that their propositions cannot be easily negated, so that there is little room offered for negotiation. After all, every statement, even if based upon very accurate data, is not definitive. Evidence of this is the constant evolution of sciences that base their arguments upon negation of propositions within the field.

On the whole, we can talk about different social needs constructing different disciplines in the research area. In addition, and according to the results of our analysis, this construction of knowledge is reflected differently in academic discourse. Regarding interactional elements, soft sciences, such as Marketing, will use a higher rate of these elements in order to show willingness for negotiation. In the case of hard sciences, these elements will also appear, although at a much lower level. The nature of the data in these sciences will determine the amount of hedges inserted in the discourse.

To sum up, we believe that differences in appearance of hedges in the three disciplines mainly depend on the nature of the data; on which point within the scientific continuum (abstract-concrete) a discipline is located. For example, the data in our analysis reveal that Biology could be found on a rather middle point within this continuum. Such are the results derived from a moderate presence of hedges in contrast to Marketing and Mechanical Engineering, positioned towards the two extremes of this continuum. On the other hand and with view to future research, there is still room for analysis of "mixed sciences" such as Biology, dividing the Research Articles by parts according to the different data used in them. Our hypothesis consists in a high variation in terms of occurrence of interactional elements depending on the nature of the data used in each part of the RA. This hypothesis would be based on the results drawn from the analysis of this paper that seems to reveal a much stronger presence of hedges in soft sciences than in hard sciences. According to this, "mixed sciences” like Biology, showing a variety of subject areas in one RA, would present different rates of hedges: these rates would be higher in those parts of the RAs handling abstract data than in those where the data are more concrete. 


\section{References}

Alley, Michael (1987): The Craft of Scientific Writing. NJ: Prenctice-Hall, Inc.

Backhouse, Roger, Tony Evans and Willie Henderson (1993): "Exploring the Language and Rhetoric of Economics". In W. Henderson, T. Evans and R. Backhouse ed., Economics and Language. London and New York: Routledge, 1-20.

Bazerman, Charles (1984): "Modern Evolution of the Experimental Report in Physics: Spectroscopic Articles in Physical Review, 1893-1980" Social Studies of Science, 14: 163193.

Bhatia, Vijay (1993): Analysing Genre. Language Use in Professional Settings. London and New York: Longman.

Bloor, Thomas and Meriel Bloor (1995): The functional analysis of English. A Hallidayan approach. London: Arnold.

Bolsky, Morris (1988): Better Scientific and Technical Writing. Englewood Cliffs, NJ: Prentice-Hall.

Booth, Vernon (1985): Communication in Science: Writing and Speaking. Cambridge: Cambridge University Press.

Boyle, Robert (1772.): A Proëmial Essay... with Some considerations touching experimental essays in General. In Works ed. T. Birch, 299-318. London [Originally Published in 1661]

Cutting, Joan (2002): Pragmatics and Discourse. A Resource Book for Students. London: Routledge.

Crismore, Avon, Raija Markannen and Margaret Steffensen (1993): "Metadiscourse in persuasive writing: a study of texts written by American and Finish American university students". Written communication. Vol. 5, 39-71.

Dafouz, Emma (2003): "Metadiscourse revisited: A contrastive study of persuasive writing in professional discourse”. Estudios Ingleses de las Universidad Complutense 11: 29-52

Flowerdew, John (ed.) (2002): Academic Discourse. London: Longman. . (2002a): Introduction: Approaches to the analysis of academic discourse in English". In John Flowerdew (ed.): 1-18

Halliday, Michael and James Martin (1993): Writing Science: Literacy and Discursive Power. Pittsburgh: University of Pittsburgh Press.

Hedge, M.N. (1994): A Coursebook on Scientific and Professional Writing in Speech-Language Pathology. San Diego, CA: Singular Publishing Group Inc.

Hübler, Alex (1983): Understatements and Hedges in English. Amsterdam: John Benjamins.

Hyland, Ken (1998): Persuasion and context: the pragmatics of academic metadiscourse. Journal of Pragmatics, 437-455.

(2000): Hedges, Boosters and Lexical Invisibility: Noticing Modifiers in Academic Texts. Language Awareness (Garret, P ed.). Vol. 9, № 4, 179-197.

Hyland, Ken (2005): Metadiscourse. London: Continuum.

Koutsantoni, Dimitra (2004): Attitude, certainty and allusions to common knowledge in scientific articles. Journal of English for Academic Purposes 3: 163-182.

Lyons, John (1977): Semantics Vol. 2. Cambridge: Cambridge University Press.

Maher, John Christopher (1992): International Medical Communication in English. Ann Arbor. MI: The University of Michigan Press.

Markkanen, Raija and Schröder Hartmut (ed.) (1997): Hedging and Discourse. Approaches to the Analysis of a Pragmatic Phenomenon in Academic Texts. Berlin and New York: Walter de Gruyter. 
McCloskey, Deirdre (1994): Knowledge and Persuasion in Economics. Cambridge: Cambridge University Press.

Mur, Pilar (2007): A contribution to the study of metadiscourse in Business Management RAs in English and Spanish: a corpus-driven approach. Universidad de Zaragoza.

Myers, Greg (1989): “The pragmatics of politeness in scientific articles”. Applied Linguistics 10 (1): 1-35.

Swales, John (1990): Genre Analysis. Cambridge: Cambridge University Press.

Tognini-Bonelli, Elena (2001): Corpus Linguistics at Work. Amsterdam and Philadelphia: John Benjamins.

Trimble, Louis (1985): English for Science and Technology: A discourse approach. Cambridge: Cambridge University Press.

Vande Kopple, William (1985): "Some exploratory discourse on Metadiscourse". College composition and communication. Vol. 36, 82-93.

Varttala, Teppo (2001): Hedging in Scientifically Oriented Discourse: Exploring Variation according to Discipline and Intended Audience. Electronic dissertation. Acta Electronica Universitatis Tamperensis. Retrieved March 20, 2007 Available: [http://acta.uta.fi].

Yule, George (2000): Pragmatics. Oxford: Oxford University Press.

\section{Appendix A}

Research Articles

Marketing (49,328 words; range: 8,911-14,813)

Desmeules, Rémi (2002): The Impact of Variety on Consumer Happiness: Marketing and the Tyranny of Freedom. Academy of Marketing Science Review. Vol. N. 12. Electronic version. Retrieved March 5, 2007 from:http://www.amsreview.org/articles/desmeules122002.pdf (11,871 words)

LaTour, Michael, Tony Henthorne, and Kathryn Braun-LaTour. (2003): Is A Cigar Just A Cigar? A Glimpse At The New-Age Cigar Consumer. Academy of Marketing Science Review. Vol. N. 12. Electronic version. Retrieved March 5, 2007 from: http://www.amsreview.org/articles/latour12-2003.pdf (8,911 words)

Woodhall, Tony (2003): Conceptualising 'Value for the Customer': An Attributional, Structural and Dispositional Analysis. Academy of Marketing Science Review. Vol. N. 12. Electronic version. Retrieved March 5, 2007 from: http://www.amsreview.org/articles/woodall122003.pdf (13,733 words)

Peters, Linda and Keith Fletcher (2004): A Market-Based Approach to Understanding Communication and Teamworking: A Multi-Disciplinary Literature Review. Vol. N. 2. Electronic version. Retrieved March 5, 2007 from: http://www.amsreview.org/articles/peters02-2004.pdf (14,813 words)

Biology (39,537 words; range: 4,054-13,749)

Huey, Chia, Madhu Chetty and Shyh Wei (2007): Characteristics of predictor sets found using differential prioritization. BioMed Central publications. Electronic version. Retrieved March 5, 2007 from: http://www.almob.org/content/2/1/7 (9,694 words)

Burr, John, Stephanie Kimzey, David Randolph and Jonathan Green (2001): CD28 and CTLA4 Coordinately Regulate Airway Inflammatory Cell Recruitment and T-Helper Cell Differentiation after Inhaled Allergen. American Journal of Respiratory Cell and Molecular 
Biology Vol. 24. Electronic version. Retrieved March 5, 2007 from: http://ajrcmb.atsjournals.org/cgi/reprint/24/5/563 (4,054 words)

Austin1, J., D. Shindell, S. R. Beagley, C. Brühl, M. Dameris, E. Manzini, T. Nagashima, P. Newman, S. Pawson, G. Pitari, E. Rozanov, C. Schnadt, and T. G. Shepherd (2003): Uncertainties and assessments of chemistry-climate models of the Stratosphere. Atmos. Chem. Phys., 3, 1-27. Electronic version. Retrieved March 5, 2007 from: http://www.atmos-chem-phys.org/acp/3/1/ (13,749 words)

Köhler, P., J. Schmitt and H. Fischer (2006): On the application and interpretation of Keeling plots in paleo climate research deciphering 13C of atmospheric CO2 measured in ice cores. Biogeosciences Discuss., 3, 513-573. Electronic version. Retrieved March 5, 2007 from: http://www.biogeosciences-discuss.net/3/513/2006/ (12,040 words)

Mechanical Engineering (17,357 words; range: 2,114-5,270)

Gáspár Zsolt and Robert Németh (2005): Shape Finding of an Extremely Twisted Ring. Journal of Computational and Applied Mechanics, Vol. 6., No. 1., pp. 39-52. Electronic version. Retrieved March 5, 2007 from: http://mab.mta.hu/ szeidl/files/6-1/6-1-GasparNemetV6N1.pdf\#details (5,270 words)

Mochnacki, Bohdan and Edyta Pawlak (2005): Application Of The Generalized Fdm For Numerical Solution Of Non-Linear Thermal Diffusion Problems. Journal of Computational and Applied Mechanics, Vol. 6., No. 1, pp. 107-113. Electronic version. Retrieved March 5, 2007 from: http://mab.mta.hu/ szeidl/files/6-1/6-1-Mochnacki-PawlakV6N1.pdf\#details (2,114 words)

Švantner, Michal (2003): Numerical Support For Residual Stress Measurement By The Hole Drilling Method. Journal of Computational and Applied Mechanics, Vol. 6, No. 1, pp. 219235. Retrieved March 5, 2007 from: http://mab.mta.hu/ szeidl/files/6-1/6-1-SvantnerV6N1.pdf\#details (5,056 words)

Hegyi, Dezso and Kristian Hincz (2004): Long-Term Analysis Of Prestressed Membrane Structures. Journal of Computational and Applied Mechanics, Vol. 6., No. 2., pp. 219-235. Electronic version. Retrieved March 5, 2007 from: http://mab.mta.hu/ szeidl/files/6-2/6-2HegyiHinczMiKTeX-V6N2.pdf\#details (4,917 words) 